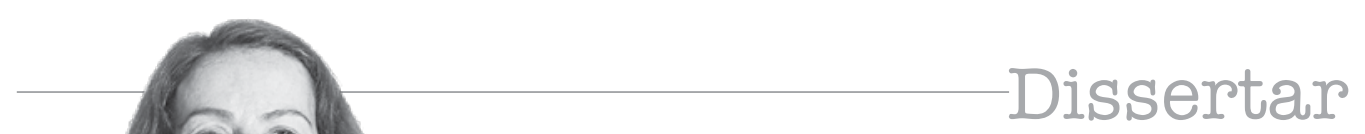

\title{
Prova como instrumento de aprendizagem
}

\section{Test as an instrument of learning \\ Examen como herramienta de aprendizaje}

Este artigo registra uma prática vivenciada com outros docentes universitários cujo propósito tem sido compartilhar aspectos técnico- pedagógicos sobre construção de questões de prova. Tenta desmistificar a concepção de prova como verificação descontextualizada, questões improvisadas e, muitas vezes, confusas em suas proposições. Para se integrar ao processo de ensino-aprendizagem, como um dos instrumentos de avaliação dos alunos, a prova deve propor questões estruturadas de modo a provocar leitura, reflexão e evidências de habilidades e competências, transformando-se, também, em mais um momento de estudo e reflexão tanto para o docente quanto para o estudante universitário.
This article reports a practice experienced with other academics whose purpose has been to share technical and pedagogical aspects of test construction issues. Attempts to demystify the concept of evidence as decontextualized verification, impromptu questions and, often confusing in their propositions. To integrate the teaching-learning process, as an instrument for the evaluation of students the test must offer structured questions so as to cause reading, thinking and evidence of skills and competences, becoming, also, in another moment of study and reflection for both the teacher and for the college student.
En este artículo se registra una experiencia práctica desarrollada con otros académicos, cuyo propósito ha sido compartir los aspectos técnicos y pedagógicos sobre la organización de cuestiones de pruebas. Lo intento es desmitificar el concepto de la prueba desvinculada del proceso de enseñanza, presentando preguntas improvisadas y confusas en sus proposiciones. Como uno de los instrumentos de evaluación de los estudiantes, las pruebas deben ser estructuradas bajo criterios pedagógicos, estimular la lectura, la reflexión y evidencias de habilidades, llegando a ser, también, otro momento de estudio y reflexión para el maestro y para el estudiante universitario.
Palavras-chave: avaliação, prova, ensino, instrumento de aprendizagem.

\section{Autora:}

\section{Prof ${ }^{a}$. Dr . Ana Maria Monica Machado de Oliveira}

Doutora em Ciências Pedagógicas: Universidade de Havana; Mestre em Educação: Universidade Federal do Rio De Janeiro; Especialista em Avaliação Institucional: Unb/ Cátedra Unesco; Prof. titular da Universidade Estácio de Sá; Assessora pedagógica da Diretoria de Educação à Distância - Universidade Estácio de Sá; Professora dos cursos de Pedagogia e Licenciatura em Educação Física.

E-mail: anamonica.machado@gmail.com

\section{Introdução}

Este artigo tem a pretensão de compartilhar alguns cuidados técnico-pedagógicos para fortalecer a função didática das provas, quando estas incluem itens ou questionamentos que estimulem os professores a repensarem sobre os tópicos estudados, os alunos sobre seus próprios desempenhos e ambos sobre condições de ensino oferecidas e vivenciadas.

O processo ensino-aprendizagem se efetiva nos procedimentos de mediação didática entre professor e aluno, através de feedbacks contínuos, para que estes possam superar suas dificuldades ou avançarem em suas práticas de ensino e de aprendizado. As provas realizadas pelos estudantes, ao longo do curso, fazem parte desta dinâmica e devem ter uma função didática e que neste estudo são compreendidas como um dos instrumentos que devem subsidiar os procedimentos de avaliação formal, previstos nos projetos pedagógicos dos cursos.

O papel da avaliação, subsidiado por distintos instrumentos, assume importância porque põe em evidência os resultados de aprendizagem que os procedimentos de ensino propiciaram. Mas para que isto aconteça é necessário que os instrumentos ou técnicas de avaliação se articulem substantivamente com o processo vivenciado.

Nessa perspectiva, avaliação permite conhecer, analisar e interpretar os resultados do ensino, constatando-se de modo criterioso as mudanças no nível qualitativo do aprendizado dos alunos e das condições de ensino, fortalecendo hábitos de estudo, essenciais para construção autônoma e cooperativa do conhecimento.

Os resultados da avaliação tendem a melhorar qualitativamente, na medida que as condições de ensino e os procedimentos adotados para aferição de resultados são aperfeiçoados, pois a responsabilidade por desempenhos insatisfatórios não depende apenas dos alunos. Sendo assim, para avaliar é preciso interpretar os resultados obtidos e as condições oferecidas para o alcance desses resultados.

No contexto dos cursos de graduação, avaliação se associa à “examinação', como observa Luckesi (2010). Na prática, o 
que se observa é classificação dos resultados numa escala de 1 a 10 , quando "o ponto de vista das relações pedagógicas, diversamente dos exames, a avaliação exige uma postura democrática do sistema de ensino e do professor (...) A responsabilidade por desempenhos inadequados não depende só do aluno, nem só do professor, porém minimamente, da escola e, abrangentemente, do sistema como um todo".

Além disso, os exames propostos, muitas vezes, não expressam as intenções declaradas pelos professores avaliadores. "Pesquisa realizada por Custódio (1996, apud SANMARTÍ: 2009, P.75) demonstrou que não há coincidência entre o que os professores entendem como objetivo importante de aprendizagem dos alunos e as perguntas que propõem para sua avaliação”.

$\mathrm{O}$ autor comenta que "...embora os professores digam que querem estimular os alunos a pensar, estabelecer relações, a deduzir, hierarquizar, a serem criativos (...,) a maioria dos objetos de avaliação não requer a demonstração destas capacidades . Ao contrário, somente "estudando" no dia anterior é suficiente para ser aprovado (SANMARTÍ: 2009,P.75 )

Os professores universitários, muitas vezes, têm contato com a turma, durante um ou dois semestres e são responsáveis pelo acompanhamento do processo, o que reforça a necessidade de utilizar instrumentos de verificação que desafiem o aluno a pensar, estudar e aprender.

Do ponto de vista educacional os critérios de avaliação devem atender alguns princípios:

- Compromisso educacional com o projeto político-pedagógico da Instituição e do Curso.

- Compromisso com aprendizado dos alunos, pois os instrumentos utilizados, inclusive a prova, devem provocar o pensamento reflexivo e é por isso é considerada, também, como um momento de estudo.

- Qualidade técnico-pedagógica dos instrumentos e técnicas válidos para medir ou verificar resultados. Como qualquer instrumento de aferição, deve zelar pela consistência de suas informações e, por sua relevância, para formação do aluno, norteado por princípios éticos.

- Coerência com os objetivos e com a abordagem teórico-prática dos conteúdos das aulas desenvolvidas na disciplina e os autores e textos privilegiados.

- Transparência na proposição de critérios. $O$ aluno deve conhecer e opinar sobre as regras do jogo e estas devem valorizar o aprendizado em seus aspectos formativos e informativos.

- Autonomia no aprendizado - Ao ser avaliado, o aluno busca formas alternativas de auto-estudo de acordo com seu próprio estilo de aprendizagem, como por exemplo: fazer esquemas, resumir, ler em voz alta, conversar com os colegas ou desenhar. A observação da realidade mostra que as agendas de trabalhos acadêmicos e as datas das provas mobilizam os alunos, mesmo os que se mostraram negligentes. Parece que esta conduta, durante o período de aulas, faz parte da cultura e do senso comum no contexto universitário.

- Trabalho cooperativo mediante a disponibilidade de um ambiente de aprendizagem, no qual o aluno tenha oportunidades para dialogar, trocar idéias, dirimir suas dúvidas e compartilhar estudos com o docente e demais estudantes.

\section{Funções da avaliação}

As funções da avaliação se revelam na prática docente e são intimamente articuladas, dependendo do foco privilegiado pelo avaliador em relação ao aprendizado dos alunos: Diagnosticar? Formar? Classificar?
Avaliação diagnóstica subsidia as demais funções ao identificar dados relativos ao aluno como, por exemplo: habilidades de estudo, nível de conhecimento em relação à disciplina, dificuldades de aprendizagem, características pessoais e socioculturais etc. Permite, também, identificar dados relativos ao professor e às condições oferecidas para o estudo da disciplina. Esta função sinaliza fragilidades e potencialidades dos avaliados e dos avaliadores.

A função formativa busca alternativas para os aspectos diagnosticados e ocorre durante todo processo ensino-aprendizagem, nos momentos em que o professor propõe novas alternativas de mediação de estudo ou novas explicações para que o aluno supere dificuldades de aprendizagem ou avance seus conhecimentos em relação à disciplina.

A avaliação formativa preocupa-se em redimensionar o processo de ensino de modo a introduzir melhorias nas condições pedagógicas para o aprendizado dos alunos.

A avaliação classificatória ou somativa permite aferir até que ponto os objetivos visados foram alcançados. Visa à promoção ou classificação do aluno. Os resultados da avaliação somativa tendem a ser melhores quando as funções diagnóstica e formativa são aplicadas ao longo do processo.

De que modo os resultados da avaliação podem contribuir para melhorar o processo ensino-aprendizagem?

Não existem receitas, mas existem procedimentos pedagógicos que revelam intenções educacionais comprometidas com práticas inovadoras. As atividades, tarefas, provas, etc, não podem ter um fim em si mesmas. Devem ser propostas se os objetivos das mesmas forem significativos para formação do aluno. Para avaliar é preciso interpretar os dados coletados e os resultados obtidos pelos estudantes. Não adianta alcançar uma pontuação elevada, média ou baixa, se esta qualificação não for interpretada. Alguns questionamentos podem ajudar nesta interpretação:

- Quais as principais dificuldades diagnosticadas?

- O que pode ser feito para superá-las?

- O que os resultados dos alunos revelam?

- Quais os pontos favoráveis e desfavoráveis sinalizados pelos resultados?

- Como superar os pontos desfavoráveis?

- Como manter o padrão de qualidade?

Em muitas ocasiões, observamos alunos individualmente ou em trabalhos feitos em grupos e que, apesar de terem obtido notas elevadas, não "vibraram" com suas conquistas. Por que será? Possivelmente porque não foram desafiados a se autossuperarem e, mesmo assim, conquistaram graus elevados sem esforço e aprofundamento.

Do mesmo modo, alguns professores avaliam os alunos com instrumentos frágeis do ponto de vista pedagógico, apóiam-se em critérios autoritários, transformando a prova num mecanismo de punição, exclusão e gerador de baixa autoestima.

\section{Acompanhamento do aprendizado: técnicas e procedimentos}

De um modo geral, os professores avaliam os aspectos formativos como interesse e participação, compromisso com horários e cumprimento de tarefas, atitude pessoal em relação aos colegas e aos professores. Na maioria das vezes, estes aspectos são avaliados de modo subjetivo, embora, muitas vezes, ajudem o professor-observador a interpretar resultados.

Quanto aos aspectos formativos ou cognitivos, os principais instrumentos utilizados são: trabalhos individuais, trabalhos em grupo, provas objetivas de múltipla escolha e provas dissertativas. 
A prova objetiva de múltipla escolha apresenta um enunciado com opções de respostas plausíveis para o aluno interpretar as informações e escolher a opção de resposta correta em relação à proposição do enunciado.

$\mathrm{Na}$ questão dissertativa, o aluno constrói a resposta. Os enunciados das questões dissertativas podem solicitar respostas diretas e objetivas ou podem solicitar respostas que envolvam subjetividade e criatividade dos alunos, pois exigem seu posicionamento pessoal, que deve ser apoiado em argumentações afinadas com a área de conhecimento avaliada.

Vamos conferir exemplos de questões objetivas e dissertativas que focalizam o mesmo objetivo?

Exemplo de questão de múltipla escolha

Tópico de conteúdo: Obrigatoriedade de ensino: aspectos legais.

Objetivo: Identificar mecanismos de controle da obrigatoriedade previstos na Constituição.

Cabe ao Poder Público oferecer condições para garantir o direito à educação básica e o cumprimento da obrigatoriedade do ensino. O mecanismo mais abrangente de controle de obrigatoriedade previsto na Constituição é:
( ) salário-família
( ) censo escolar
( ) salário educação
( ) registro de frequência

Exemplo de questão dissertativa com resposta de cunho objetivo

Tópico de conteúdo: Obrigatoriedade de ensino: aspectos legais.

Objetivo: Identificar mecanismos de controle da obrigatoriedade previstos na Constituição

A obrigatoriedade do ensino deve ser garantida pelo Poder Público. Consulte o artigo 208 da Constituição Brasileira de 1988 e destaque, pelo menos, três recomendações diretamente relacionadas ao controle da obrigatoriedade do ensino fundamental.

Tópico de conteúdo: Obrigatoriedade de ensino: aspectos legais. subjetivo

Modelo de questão: dissertativa com resposta de cunho

De acordo com a Constituição, o direito à educação básica deve ser garantido. Comente, pelo menos, duas responsabilidades do Estado diretamente relacionadas à garantia deste direito, no ensino fundamental.

\section{Nível de exigência das provas}

As provas devem ser coerentes com os objetivos propostos, apresentar cuidados técnicos na redação das questões, adotar procedimentos criteriosos na correção, aferição e interpretação dos resultados.

O nível de complexidade deve considerar os processos mentais envolvidos, as habilidades de estudo e as competências adquiridas ao longo do curso.

Fazer provas representa um dos ritos da cultura estudantil e acadêmica e, como tal, deve ser explicitado de modo que avaliadores e avaliados desmistifiquem este momento como punição e passem a considerá-lo como um dos procedimentos de ensino e aprendizagem, sendo assim, as questões ou proposições de trabalhos "para nota", como dizem os alunos, devem ter uma função didática e revisar ou ampliar o conhecimento do aluno.

Observamos provas que incluem contextos com exemplos, reportagens, fragmentos de texto extraídos de autores, charges, poesias que além de verificarem o objetivo despertam curiosidade ou ampliam o universo de informações do examinado.

A questão do ENADE- 2005 é um bom exemplo:

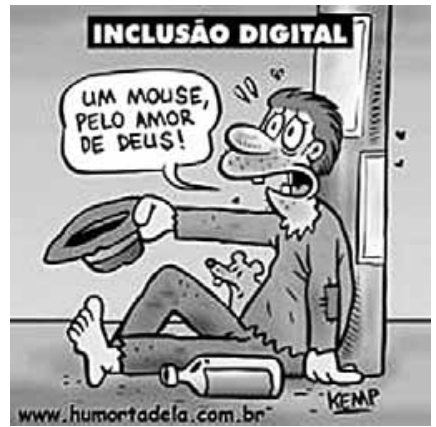

-"O Governo Federal deveria promover a inclusão digital pois a falta de acesso às tecnologias digitais acaba por excluir socialmente o cidadão, em especial a juventude.” ( JB online ) .

Comparando a proposta expressa no texto com a charge, pode-se concluir que:

( ) o conhecimento da tecnologia está democratizado no Brasil.

( ) a preocupação social é preparar especialistas para o domínio da informática

( ) o apelo à inclusão digital atrai jovens para o universo da computação

( ) o acesso à tecnologia digital está perdido para as comunidades carentes

( ) a dificuldade de acesso ao mundo digital torna o cidadão um excluído social

A leitura da prova deve ser agradável, evitando informações desnecessárias que possam complicar sua interpretação; enfim, um "momento privilegiado de aprendizagem", como afirma Moretto (2007). Em geral, as questões contextualizadas cumprem sua função didática, pois estimulam o aluno a situar o tópico de conteúdo com informações ou dados pertinentes e necessários para dar sentido ao enunciado.

De acordo com as orientações do MEC, deve-se evitar confundir a contextualização com textos ou informações desvinculadas do que se pretende perguntar, utilização de linguagem prolixa desnecessária e ausência de desafios que estimulem a articulação de idéias, ou seja, pseudocontextualização.

Além da contextualização, outras características devem ser consideradas na construção dos itens ou questões de provas:

- Relevância: valorizar tópicos de conteúdos e habilidades que contribuam para formação do aluno.

- Objetividade: redigir questões (objetiva, múltipla escolha ou discursiva) com frases bem estruturadas e palavras de significado preciso.

- Propriedade do conteúdo: adotar como parâmetro rigor científico, atualização temática, evitando impropriedades terminológicas.

- Abordagem interdisciplinar: encaminhar questionamentos que favoreçam a integração de conhecimentos de diferentes matérias ou disciplinas. 
- Aspectos étnicos e culturais: “As questões não podem conter informações, situações, exemplos, vocabulários, informações, etc. que possam caracterizar como viés cultural, ou que se revelem posturas de discriminação e preconceito em relação a gêneros, etnias, profissões, crenças, religiões, ideologias, linhas teóricas ou de outra natureza" (MEC/INEP/ 2002: P. 22).

\section{Construção de questões de prova}

Formular questionamentos, propor roteiros de trabalhos, preparar provas fazem parte do cotidiano do professor universitário, responsável pela legitimação do rendimento acadêmico dos alunos.

Existem vários instrumentos e técnicas de medida e avaliação como observação, entrevistas, portifólios, trabalhos acadêmicos e provas. Estas devem espelhar coerência com os objetivos, metodologia de ensino, nível de abrangência e complexidade do conteúdo.

QUANTO AO OBJETIVO/CONTEÚDO DA DISCIPLINA:

- Valorizar níveis cognitivos diferenciados, como por exemplo, análise e interpretação de idéias, aplicação de conceitos, valorizando habilidades e competências relevantes para formação do aluno.

- Construir enunciados que estimulem o aluno a pensar para responder.

- Verificar se, realmente, a questão mede o objetivo que se propõe a medir. A organização de uma planilha de especificação favorece este procedimento.

- "Não formular questões sobre temas polêmicos ou que permitam várias abordagens. Este tipo de questão pode dar margem a mais de uma reposta correta ou nenhuma resposta correta" (MEC/INEP. 2002).

- Não confundir enunciado com instrução para responder à questão, evitando encaminhamentos como "podemos afirmar que..." ou "assinale a resposta correta", seguidos de opções, que, em geral, é a instrução da prova.

- Ao ler o enunciado o leitor deve saber o que se espera dele, mesmo sem ler as alternativas.

\section{QUANTO À FORMA:}

- Checar se o enunciado da questão está claro para leitura e entendimento do aluno.

- Não usar termos que remetam a uma verificação espacial nas opções ou na prova, como por exemplo: itens acima, questão $\mathrm{X}$, considere o trecho da questão $\mathrm{Y}$.

- Evitar predominância de questões de múltipla escolha com a mesma formatação.

- Revisar as questões, observando se há duas respostas possíveis ou iguais.

- Concentrar, na medida do possível, a maior parte da redação no enunciado da questão, visando obter opções de respostas curtas e homogêneas.

- Observar a redação das opções de modo a evitar que uma ou algumas se destaquem devido à quantidade de informação.

- Evitar incluir nas opções palavras ou expressões que aparecem também no enunciado.

- Destacar palavras ou expressões, utilizando letra maiúscula, ao escrever enunciados ou respostas que incluam palavras ou expressão negativas (NÃO, INCORRETO).

- Não usar dupla negativa (no enunciado e na opção de resposta).

- Observar a forma e a distribuição gráfica e gramatical, evitando "pistas".

\section{FAGILIDADES OBSERVADAS NA PROPOSIÇÃO} DE QUESTÕES:

Questões sem enunciado são aquelas em que o avaliador confunde os alunos, escrevendo apenas o comando da prova, por exemplo:

- "Assinale a resposta ou a afirmativa correta". Correta em relação a quê? O aluno precisa advinhar o que professor deseja. Quando a prova é presencial, normalmente o professor aplicador acrescenta, oralmente, as informações e completa as lacunas técnicas de suas questões.

- Muitas vezes o enunciado solicita que o aluno decida sobre tópicos, afirmativas ou exemplos. Nem sempre as opções seguem ao padrão solicitado.

Tipos e exemplos de questões objetivas de múltipla escolha Dentre os tipos de questões objetivas destacam-se: complementação simples ou resposta única, interpretação e resposta múltipla.

- Questão complementação simples ou resposta única

- Questão de Interpretação

A prática educativa revela pressupostos teóricos que podem ser identificados com diferentes abordagens pedagógicas. Quando um professor valoriza predominantemente a reprodução de idéias e conceitos em questões de provas, ele está de acordo com fundamentos da abordagem:
(A) Cognitivista
(B) Humanista
(C) Tradicional
(D) Tecnicista

A questão de múltipla escolha de interpretação propõe uma situação-problema, a partir do enunciado, pode ser um texto, o relato de um caso, uma tabela, um gráfico, uma figura, um mapa ou ilustração que devem ser apresentados com as devidas referências.

\section{Exemplo:}

$\mathrm{O}$ intelectual pesquisador que se preocupa em listar problemas sociais e emitir opiniões sobre questões que afligem as comunidades de baixa renda "se torna como o jornal da TV; ele apenas emite, apenas informa sem interagir, sem politizar. Portanto é um intelectual que não sabe aprender" (FREIRE; NOGUEIRA: 1989 P.40).

Em relação aos conhecimentos peculiares aos diferentes tipos de cultura, a opção que exemplifica a crítica apresentada no texto é:

(A) Os pesquisadores diagnosticam a realidade

(B) Os saberes humanos são valorizados

(C) A cultura erudita transforma a realidade

(D) O senso comum guarda ensinamentos

\section{Questão de resposta múltipla}

"A questão de reposta múltipla consiste de três ou quatro afirmações, relacionadas com o tema explicitado no enunciado e de um conjunto de respostas, onde são apresentadas as alternativas de resposta, propriamente ditas, sendo que em cada uma delas consta qual (ais) afirmação (ões) dentre as apresentadas é (são) verdadeira (s), em relação à proposta do enunciado da questão"( MEC: 2002, p.26 ).

O uso deste tipo de questão se justifica quando há situações em que admitem mais de uma possibilidade de resposta.

Ao propor este tipo de questão é importante observar a coerência das possibilidades de respostas certas que, em geral, 
são afirmativas, tópicos, características, fragmentos de textos, etc.

Exemplo:

Existem professores que se recusam a aceitar o computador, argumentando que ele não é necessário à sua prática. Esta atitude, muitas vezes, encobre o temor ao novo. Por outro lado,

Existem aqueles que vêem nessa ferramenta o instrumento que transformará sua prática resolvendo todos os problemas que enfrentam em seu fazer pedagógico, inclusive o desinteresse dos alunos pelas aulas. tador deve:

É consensual, no entanto, que a utilização do compu-

I - ser vista como adição ao sistema de um novo recurso para melhorar a aprendizagem;

II - estar comprometida com a reorientação da educação, numa perspectiva transformadora;

III - ser acompanhada do estímulo à criatividade docente;

IV - manter preservada a consciência crítica de professores e alunos.

Estão corretas apenas as afirmações:
(A) I e IV.
(B ) II e III.
(C) I, II e III.
(D) I, III e IV.
( E ) II, III e IV.

$\overline{\text { Fonte: ENC/INEP/ Pedagogia } 2001}$

\section{Níveis de complexidade das questões}

As provas devem incluir questões que valorizem habilidades de leitura, interpretação de fatos, conceitos, idéias, fórmulas e, sobretudo, aplicação dos estudos realizados em situações contextualizadas, casos concretos ou situações que estimulem o aluno a pensar.

Embora existam diferentes taxionomias (sistemas de classificação) para explicitar o que se pretende em termos de evidências de resultados de aprendizagem, as categorias estudadas pelos pesquisadores Bloom, B.; Engelhart, M.; Hill, Walker; kratwohkl, iniciada no final dos anos 40 e que ficou conhecida no Brasil como taxionomia de Bloom, no início dos 60 tem sido revisitada e muito aplicada.

Neste artigo abordaremos o domínio cognitivo e apenas três categorias memorização ou evocação, compreensão e aplicação.

Questões de memorização verificam conhecimento de dados específicos, terminologias, datas, fórmulas, nomes de teorias, fatos etc, quase sempre, apelam para evocação ou reconhecimento.

As questões de compreensão verificam a interpretação de idéias, fatos, conceitos, abstrações, como, por exemplo, perceber a contradição entre dois textos ou questões que permitam identificar as características de uma teoria estudada.

As questões de aplicação que verificam a utilização do conhecimento estudado em situações novas, estimulando o aluno a transferir os conhecimentos, idéias, informações de que dispõe para responder.

\section{Questões dissertativas}

As questões dissertativas verificam resultados de aprendizagem em que o examinando ou o aluno constrói a resposta, utilizando palavras próprias. Enquanto as objetivas valorizam as habilidades de leitura interpretativa, as questões dissertativas valorizam a organização do pensamento de forma escrita.
Algumas habilidades e competências podem ser evidenciadas pelo aluno ao responder uma questão dissertativa, como por exemplo:

- Apresentar explicações ou soluções para problemas apresentados.

- Aplicar conceitos ou conhecimentos adquiridos durante as aulas.

- Estabelecer relações entre causas e conseqüências.

- Posicionar-se em relação a alguma idéia, situação ou problema, argumentando favoravelmente ou desfavoravelmente.

- Expressar conclusões ou inferências com base em dados ou elementos analisados.

- Organizar idéias de modo coerente e lógico e expressá-las na escrita.

- Formular conclusões a partir de proposição ou assertivas.

Em resumo, a estrutura das questões dissertativas pode ser sistematizada na fig. 1 .

\section{Sugestão de estrutura básica de questão dissertativa}

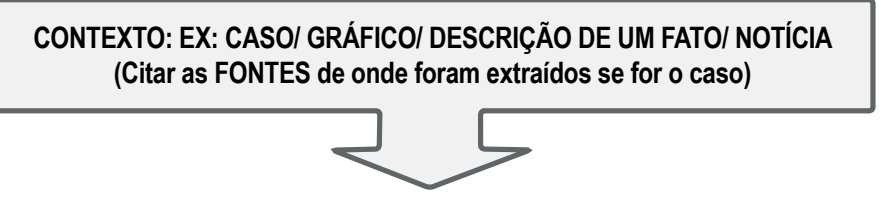

ENUNCIADO OU PROPOSIÇÃO DA PERGUNTA (ARTICULANDO O QUE SE ESPERA DO ALUNO COM O CONTEXTO APRESENTADO

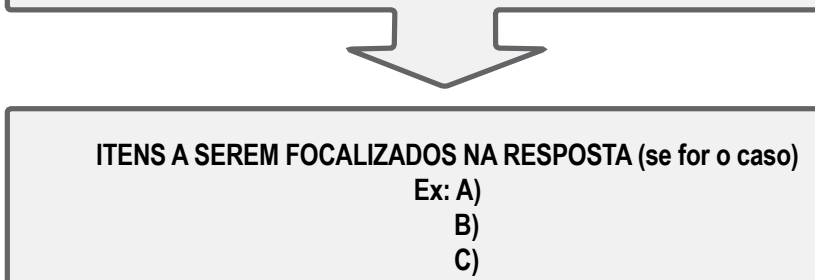

(Na chave de correção o professor especifica a pontuação, valorizando os itens, a partir de critérios considerados relevantes na disciplina)

\section{Fragilidades que devem ser evitadas}

Muitas vezes as questões dissertativas são confundidas com questões objetivas de resposta curta, em outros casos questionários de pergunta e resposta que valorizam a decoreba e até mesmo a fraude, como por exemplo:

Qual o pensador que fez a seguinte afirmativa?

Qual da data da criação da ONU?

Qual a teoria de administração que adota a concepção de homus economicus?

O que é PIB?

Do mesmo modo as questões dissertativas devem evitar proposições vagas como, por exemplo:- "Dê sua opinião"-"O que você pensa?"-- "Fale sobre...."-- " Diga o que sabe sobre..."- "Comente sobre.."

Enunciado como esses dão margem a múltiplas interpretações, que na maioria das vezes serão rejeitadas pelo avaliador, especialmente, enunciados que dão brecha para qualquer tipo de abordagem, dissimulando respostas utilizando linguagem redundante.

Além disso, tornam os critérios de correção difusos e subjetivos. 


\section{Critérios de correção}

Corrigir questões dissertativas vai além de atribuir uma pontuação. $\mathrm{O}$ avaliador assume o papel de leitor e analisa as respostas, com base em uma chave de correção, mas principalmente pela análise da resposta do aluno.

De acordo com dicionário Houaiss corrigir significa “dar forma correta, ou melhorar; pôr em bom estado, em ordem, em boa condição (o que apresenta alguma incorreção ou está em desarmonia com o todo, ou impede o seu equilíbrio...). Verificar ou avaliar a exatidão de respostas em (prova, teste etc).

Enfim antes de lançar notas ou conceitos na documentação escolar para subsidiar o histórico escolares, os docentes percorrem diferentes fases: planejar os procedimentos de avaliação, definir critérios, construir questões, aplicar provas, avaliar resultados e replanejar o processo.

\section{Considerações finais}

A pretensão deste artigo foi compartilhar algumas observações e vivencias de natureza pedagógica, numa busca dialógica de intercâmbio acadêmico sobre um tema polêmico, pois coloca o professor na condição de juiz que precisa expressar sua opinião consubstanciando-se em evidências. As provas não têm um fim em si mesmas, contudo fazem parte da cultura acadêmica e sobre as questões cabem algumas considerações:

As questões de múltipla escolha valorizam mais as habilidades de leitura e interpretação, enquanto as dissertativas valorizam organização e coerência da expressão escrita do pensamento.

Tanto as questões objetivas quanto as dissertativas, além do foco do conteúdo e do objetivo verificado, exigem cuidados técnico-pedagógicos para sua construção.

A proposição e a organização das questões devem ser compreendidas pelos alunos, que ao ler o enunciado, podem identificar o que se espera deles como resposta. Questões bem formuladas, em geral, não necessitam de explicações ou esclarecimentos complementares no momento da aplicação.

A clareza do enunciado e a contextualização favorecem o estudo e a compreensão do tema focalizado na questão. E, em alguns casos, ampliam as informações e a cultura geral dos alunos, especialmente, quando o avaliador inclui um texto literário, um gráfico atualizado, um recorte extraído do jornal etc. Deste modo a prova cumpre sua função didática e se transforma num instrumento de aprendizagem.

A preocupação pedagógica do avaliador com critérios de correções das questões dissertativas exigem mais tempo para correção, além de familiaridade com o conteúdo focado na questão.

Tanto as provas objetivas quanto as dissertativas necessitam de gabarito de correção, especialmente antes de serem aplicadas. Este cuidado, de certo modo, coloca o docente avaliador na posição do aluno a ser avaliado, além de garantir critérios coerentes para correção.

Embora existam prós e contras acerca de provas, alguns argumentam que existem aspectos legais a serem cumpridos e que o aproveitamento dos estudantes deve ser registrado, com base em evidências do aproveitamento, pois as instituições formais precisam atribuir conceitos e notas para legitimar a escolaridade de seus egressos. Outros rechaçam as provas porque confiam em seu olho clínico ou trabalham com número reduzido de estudantes o que favorece a aplicação de outros instrumentos.

Muitas vezes os estudantes não têm bom desempenho nas provas ou se frustram em decorrência de um conjunto de questões equivocadas e confusas em suas proposições.
Alguns docentes negam a existência de provas como um dos instrumentos de medida e avaliação mais pelo fato de que estas exigem tempo e estudo para sua construção do que por convicções teóricas.

As provas objetivas e as dissertativas são instrumentos de medida, ou seja, verificam e mensuram os resultados de aprendizagem. A análise e a interpretação dos resultados subsidiarão o processo de avaliação.

As provas objetivas ou dissertativas devem ser um dos instrumentos de verificação, dentre outros, do mesmo modo não deve ser excluídas, pois os processos avaliativos devem gerar oportunidades para que os estudantes façam um balanço de seus resultados.

A observação do cotidiano permite afirmar que no período de provas ou apresentação de trabalhos a presença e a participação dos estudantes tende a ser intensificada, gerando um "clima de estudo" e, além disso, a turma como um todo ganha mais visibilidade e muitas vezes aproximam os estudantes que solicitam ajuda aos alunos para esclarecer dúvidas, trocar materiais de estudo e, em alguns casos, cabular - uma espécie de ajuda clandestina . Mas este é um assunto para outro artigo, pois situa-se no âmbito do currículo oculto - aquele que se explica pelas práticas e atividades escolares não explicitadas nos documentos e nem nos planos de ensino.

\section{Referências}

BLOOM, Benjamim et al. Taxionomia dos objetivos educaionais: domínio cognitivo, v.1. RS: Editora Globo, 1976.

FREIRE, Paulo; NOGUEIRA, Adriana. Que fazer: teoria e prática em educação popular. Petrópolis: Vozes, 1993.

HOUAISS, Antonio; VILLA, Mauro Salles. Dicionário da língua portuguesa. Rio de Janeiro:Objetiva, 2001.

LUKECSI, Cipriano. Avaliação da aprendizagem: visão geral. Website: www.luckesi.com.br. Acesso em 9/9/2008

MORETTO, VASCO. Prova - momento privilegiado de estudos, não um acerto de contas. SP: Lamparina, 2007.

MEC/INEP/ PROVÃO: Manual para elaboração de provas. Brasília: 2002. MEC/INEP/ENADE. Provas. acesso em 8/9/2009.

http://www.inep.gov.br/download/enade/2005/provas/ENGENHARIA I.pdf SANMARTÍ, Neus. Avaliar para aprender. São Paulo: Armed, 2007. UNIVERSIDADE ESTÁDIO DE SÁ/ EAD. Banco de questões. 2009/2010.

VASCONCELLOS, Celso dos S. Avaliação - concepção dialéticalibertadora do processo de avaliação escolar. São Paulo: Libertad, 2007. VENTURA, Magda. Elaboração de instrumentos de avaliaçãoprovas com questões objetivas e discursivas. (impr.). Universidade Estácio de Sá, 2003. 